\title{
COVID-19 and Public Transportation: Current Assessment, Prospects, and Research Needs
}

\author{
Alejandro Tirachini \\ Universidad de Chile and Instituto Sistemas Complejos de Ingeniería, Chile
}

Oded Cats

Delft University of Technology, the Netherlands

\begin{abstract}
The COVID-19 pandemic poses a great challenge for contemporary public transportation worldwide, resulting from an unprecedented decline in demand and revenue. In this paper, we synthesize the state-of-the-art, up to early June 2020, on key developments regarding public transportation and the COVID-19 pandemic, including the different responses adopted by governments and public transportation agencies around the world, and the research needs pertaining to critical issues that minimize contagion risk in public transportation in the so-called post-lockdown phase. While attempts at adherence to physical distancing (which challenges the very concept of mass public transportation) are looming in several countries, the latest research shows that for closed environments such as public transportation vehicles, the proper use of face masks has significantly reduced the probability of contagion. The economic and social effects of the COVID-19 outbreak in public transportation extend beyond service performance and health risks to financial viability, social equity, and sustainable mobility. There is a risk that if the public transportation sector is perceived as poorly transitioning to post-pandemic conditions, that viewing public transportation as unhealthy will gain ground and might be sustained. To this end, this paper identifies the research needs and outlines a research agenda for the public health implications of alternative strategies and scenarios, specifically measures to reduce crowding in public transportation. The paper provides an overview and an outlook for transit policy makers, planners, and researchers to map the state-ofaffairs and research needs related to the impacts of the pandemic crisis on public transportation. Some research needs require urgent attention given what is ultimately at stake in several countries: restoring the ability of public transportation systems to fulfill their societal role.
\end{abstract}

Keywords: COVID-19 virus transmission, sustainability, safety, resilience, public health

(C) 2020 Alejandro Tirachini and Oded Cats

https//doi.org/10.5038/2375-091.22.1.1

ISSN: 1077-291X | Licenced under Creative Commons License Attribution - Noncommercial 4.0

The Journal of Public Transportation is published by the Center for Urban Transportation Research

at the University of South Florida 


\section{Introduction}

The rapid spread of the COVID-19 virus, which became a worldwide pandemic in a matter of weeks, has been attributed to the hypermobility of our current lifestyle, globalization, and the connectivity and accessibility of Wuhan, the first epicenter (Musselwhite, Avineri, and Susilo 2020). Since then, the COVID-19 pandemic rapidly evolved into a situation with profound effects on lifestyle and travel worldwide, ranging from a dramatic decrease in air travel to an unprecedented increase in teleworking. These impacts resulted from governmental measures (e.g., travel restrictions and shutdowns of whole sectors in the economy) as well as individual choices to refrain from traveling in order to reduce exposure to other people and the risk of contamination.

Urban travel has declined all over the world, but not uniformly for all modes; public transportation has taken the hardest blow, as shown by survey-based data (Molloy et al. 2020; Astroza et al. 2020). This was in some cases accompanied by a reduced service supply and exacerbated by the perception of public transportation as riskier than private or personal means of transport because of the closer contact to other people that is possible, sometimes unavoidable, in public transportation vehicles and stations. Figure 1 shows the variation on the use of public transportation hubs based on Google Mobility Reports data (authors own elaboration). The baseline for the data is the median value for the corresponding day of the week, during the five-week period between January 3 and February 6, 2020 (Google 2020).

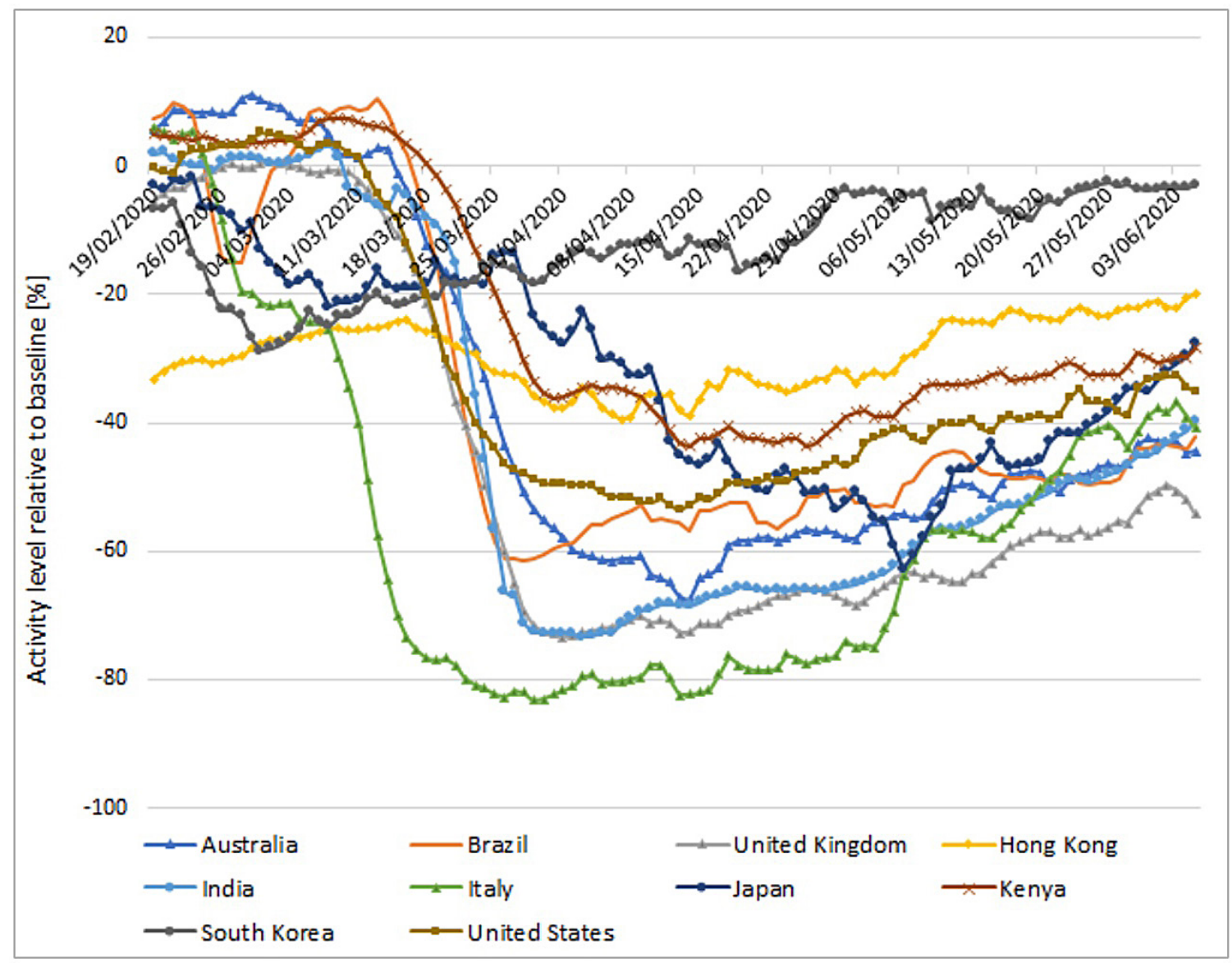

\section{FIGURE 1.}

Change in use of public transportation hubs such as subway, bus, and train stations; five-day moving average between February 15 and June 5, 2020 
The fact that a person infected with the novel coronavirus COVID-19 is contagious before showing any symptom (Javid, Weekes, and Matheson 2020; Ferretti et al. 2020) is particularly worrisome for virus exposure in public places. Several factors contribute to making public transportation stations and vehicle environments high risk for the COVID-19 contagion (UITP 2020):

1. People are confined in limited space. Contagion risk increases with the level of passenger occupancy in vehicles and stations. The discomfort associated with traveling in crowded buses or trains has increased since the COVID-19 pandemic due to the added risk of becoming infected by a potentially deadly virus for which there is no vaccine yet.

2. There might be scarce access control to identify passengers or workers who may be sick.

3. The existence of multiple surfaces, such as seats, handrails, doors, and ticket machines, that easily transfer germs.

Notwithstanding, there are ways to reduce or eliminate the risks associated with all these factors, which are reviewed in this paper. Moreover, the level of the COVID-19 contagion risk during traveling versus during activities performed at the places that people visit is unclear, as several variables intervene in determining actual risk levels in different environments.

Advice by authorities regarding the use of public transportation in response to the COVID-19 pandemic has been quite varied around the world. On one end of the spectrum, official guidelines explicitly discourage the use of public transportation. The United Kingdom clearly advises, "You should avoid using public transport where possible" and "Consider all other forms of transport before using public transport" (DfT 2020). Similarly, the Netherlands national government advises to use public transportation "only if it is really necessary and you do not have any other means of transport, and travel outside the rush hours as much as possible" (Rijksoverheid n.d.). In the United States, it is suggested that employers should "offer employees incentives to use forms of transportation that minimize close contact with others (e.g., biking, walking, driving, or riding by car either alone or with household members)" (CDC 2020b). Such positions can be accompanied by strict physical distancing rules. For instance, during May 2020 in New South Wales, Australia, the capacity of a standard 12-meter-long bus and of a train carriage have been reduced to 12 and 32 passengers, respectively (Terrill 2020).

At the other end of the spectrum, there are countries particularly in Asia that have not imposed strong restrictions or warnings. In some cities of China, bus capacity has been reduced to $50 \%$ only, allowing all bus seats to be occupied while onboard cameras check capacity compliance (Wong 2020). Metro trains in Taiwan and South Korea are running with large occupancies at peak periods, well beyond the usual COVID19 physical distancing suggestions (one or two meters of distance between people), in countries where mask use is compulsory in public places and the COVID-19 outbreak has been largely contained. Moreover, as the economy reopens after lockdown in Singapore, the COVID-19 governmental task force explicitly stated that social gatherings are still forbidden as of June 8 , but physical distancing in public transportation will not be enforced as long as passengers wear masks and do not talk to each other in order to minimize contagion risks (How and Thiagarajan 2020). The differences in recommendations and regulations by countries regarding public transportation could be explained by the differences in the current prevalence of COVID-19 in their communities, however more factors are likely at play. The appropriateness of containment measures in each country will be reassessed as the pandemic evolves.

In this paper, we analyze the critical issues pertaining to public transportation use during the COVID-19 pandemic, some of which provide insights into understanding the various approaches to public transportation use adopted in different countries, as discussed above. The COVID-19 worldwide crisis is a rapidly evolving event with rapidly increasing yet limited and inconclusive scientific evidence so far on key issues pertaining to virus 
transmission paths and the effectiveness of prevention measures. We review evidence publicly available through early June 2020 on several factors relevant to public transportation during the COVID-19 pandemic. Then we use this information as a basis to suggest a research agenda.

Some of the topics discussed refer to the COVID-19 crisis or lockdown period, in which large-scale measures to contain the spread of the virus were taken by federal, state, and local governments, usually implying the avoidance of all unnecessary travel by any means of transport. However, most of the discussion is relevant for the so-called post-lockdown phase, loosely defined as the period after the worst part of the crisis has passed, when people resume activities that have been paused because of COVID-19. This post-lockdown period might be prolonged, as it is expected to last for as long as there is no widespread immunity in the population. Furthermore, there is no certainty that new waves of widespread infection will not emerge after the first crisis.

\section{COVID-19 Effects and New Rules for the Use of Public Transport}

\section{The Emergence of Physical Distancing}

Respiratory infections such as COVID-19 are transmitted through droplets ( 5 to $10 \mu \mathrm{m}$ ) and aerosols (smaller than $5 \mu \mathrm{m}$ ) exhaled from infected individuals when breathing, speaking, coughing, and sneezing (Prather, Wang, and Schooley 2020). Although there is still plenty of uncertainty about the various ways in which COVID-19 contagion occurs (Leung et al. 2020; Han et al. 2020), airborne transmission in closed environments has been established by several authors (Morawska and Cao 2020; Shen et al. 2020; Prather, Wang, and Schooley 2020; Buonanno, Stabile, and Morawska 2020). Consequently, closed environments are generally riskier than open environments (Nishiura et al. 2020; Qian et al. 2020). Aerosols can accumulate and remain infectious in indoor air for hours (Prather, Wang, and Schooley 2020), which is the greatest challenge for public transportation and the resuming of day-to-day human activities in other closed environments during the COVID-19 pandemic. For example, guidance on the resuming of activities in workplaces highlights the relevance of natural ventilation, air filtration, and employees following strict hygiene protocols, in addition to the cleaning and disinfection especially of high-touch surfaces among several other actions (CDC 2020b).

The concept of physical distancing (also called social distancing) has emerged as one of the most widely nonpharmaceutical measures applied to prevent COVID-19 transmission. The World Health Organization (WHO) recommends keeping a distance of at least one meter from other persons (WHO 2020b), while other health organizations suggest a physical distance of two meters to reduce the risk of COVID-19 transmission (CDC 2020a). A distance of at least one meter has been found to significantly reduce the probability of COVID-19 contagion (Chu et al. 2020). The recommendation of physical distancing is, among the non-pharmaceutical prevention measures, the most significant and consequential for public transportation service deployment and use, provided that physical distancing strongly reduces the capacity of vehicles and stations to accommodate travelers. Simply put, physical distancing conflicts with the concept of public transportation (Musselwhite, Avineri, and Susilo 2020).

Current research suggests that the general advice of keeping a distance of 1.0, 1.5, or 2.0 meters from other people as a precautionary measure works in outdoor environments with short exposure times, but this physical distance rule has been challenged for indoor environments where contagion from an infected to a non-infected person has been reported at larger distances. Shen et al. (2020) report the case of a January 2020 bus trip in Ningbo, China, where a single asymptomatic infected person is believed to have transmitted the COVID-19 virus to 22 passengers (out of 67 persons in total) over two 50-minute bus rides. In this case, the passengers did not wear face masks. Current research recognizes that the duration of exposure is also relevant (Prather, Wang, 
and Schooley 2020; SAGE 2020), however as of this writing, it is still unknown how the probability of contagion increases as a function of the duration of exposure. This is particularly relevant for public transportation use in order to understand the inherent risks of long trips relative to short trips. All in all, without face protection, frequent cleaning, and ventilation, public transportation ticks all the boxes as a prime virus spreader: it is a closed environment where people might be contained for a prolonged period. In this setting, physical distancing can reduce the number of people infected if the virus is circulating, but by itself does not work to stop virus spreading if not complemented by other measures such as universal face mask use.

\section{The Use of Face Masks}

The use of face masks by asymptomatic persons as a virus containment measure has been a contentious issue particularly during the first months of the COVID-19 pandemic (Javid, Weekes, and Matheson 2020; Greenhalgh et al. 2020). Arguments against suggesting the widespread use of face masks include the initial limited evidence of their efficiency, misuse due to lack of information about how to properly wear them, and the possibility of adopting risk behaviors when wearing masks (Greenhalgh et al. 2020). For several months, the World Health Organization (WHO) recommended face mask use only for people with respiratory symptoms and for healthcare workers (WHO 2020b). On June 5, 2020, WHO revised its guidelines to suggest the use of non-medical (fabric) masks in public places including public transportation, and the use of medical masks for vulnerable populations (WHO 2020a). Following WHO, the US Centers for Disease Control and Prevention (CDC) also originally advised the general public not to wear masks, but this recommendation was updated in April 2020 to suggest the use of fabric masks in public (CDC 2020a), apparently as a substitute due to the shortage of surgical masks (Greenhalgh et al. 2020). The efficiency of different fabrics to filtrate aerosol particulates was tested by Konda et al. (2020), finding that the filtration level could be similar to that of medical masks when multiple layers are used and when different fabrics are combined (e.g., cotton and silk, cotton and chiffon).

Even though doubts over the universal use of face masks were prevalent in many countries particularly during the first months of the COVID-19 crisis, the latest research suggests that universal mask wearing is critical for the containment of COVID-19. Face masks can significantly reduce the number of infectious COVID-19 viruses in exhaled breath (Chu et al. 2020; Leung et al. 2020), particularly of asymptomatic people and those with mild symptoms (Prather, Wang, and Schooley 2020). The filtration capacity of fabric masks was found to be larger than $80 \%$ for particles $<300 \mathrm{~nm}$ and larger than $90 \%$ for particles $>300 \mathrm{~nm}$, with particular combinations of common fabrics including cotton, silk, chiffon, and flannel (Konda et al. 2020). Lately, the "precautionary principle" has been to suggest the widespread use of face masks during the COVID-19 crisis, given that the potential gains in public health are likely to largely outweigh the risks involved (Greenhalgh et al. 2020; Javid, Weekes, and Matheson 2020). At this stage, it is also clear from epidemiological data that countries that have effectively contained the spread of COVID-19, such as Taiwan, Japan, Hong Kong, Singapore, and South Korea, have enforced universal mask wearing (Prather, Wang, and Schooley 2020). The effectiveness of widespread mask adoption among the population in reducing the death rate due to COVID-19 at city or country levels has also been predicted by simulation models (Eikenberry et al. 2020; Ngonghala et al. 2020). Education on the proper use of face masks is as relevant as enforcing universal use because improperly fitting masks can reduce aerosol filtration efficiency by $60 \%$ (Konda et al. 2020).

Thus, the accumulated evidence suggests that face mask use in public transportation can be an effective way of stopping COVID-19 virus transmission only if proper masks are used and people know how to fit and handle them correctly. A campaign for face mask use needs both to make sure that proper masks are affordable 
by the general population and that people are educated about their use. Eye protection devices also reduce the probability of COVID-19 contagion (Chu et al. 2020), however their use has not been enforced for public transportation passengers. Eye protection could be considered, among other measures, for higher-risk workers such as bus drivers.

\section{Hygiene, Sanitization, and Ventilation}

Regarding enhanced hygiene and cleaning standards, it has been found that the COVID-19 virus remains infectious from hours to days on different types of surfaces, including plastic and stainless steel (Fa-Chun et al. 2020; van Doremalen et al. 2020). Therefore, physical contact with a contaminated surface is a potential mode of COVID-19 transmission. This implies frequent cleaning of high-touch surfaces in public transportation vehicles and stations as a recommended preventive measure. Sanitization of public transportation vehicles and stations has been widely adopted around the world, with various levels of intensity depending on the extent of organization and the resources available in each agency. Some guidelines already advise on the increased hygiene measures that must be put in place for public transportation staff, not only on vehicles and stations, but also in dressing rooms, meeting rooms, and management offices (GIZ 2020; UITP 2020). Rigorous evaluations on the effectiveness of these measures are lacking and much needed. In the post-lockdown period, it might be necessary to have personal protection elements and hygiene measures to reassure staff and passengers and maintain confidence in the public transportation system, even if the risk of infections is considered low (UITP 2020). Relevant information should be widely provided to users, including standards of conduct and hygiene, the correct use of masks, and avoidance of public transportation if a passenger shows symptoms such as fever and coughing (GIZ 2020).

Whether the use of air conditioning can further spread the COVID-19 virus and lead to transmission at a longer distance from the source is still unclear and likely depends on using recirculated air. Limited evidence suggests that air conditioning can play a role in contagion in indoor environments such as restaurants (Jianyun et al. 2020). CDC recommends the use of air ventilation/air conditioning systems on non-recirculation mode (CDC 2020c). Frequent ventilation of closed spaces such as public transportation vehicles is usually recommended as a preventive measure (Buonanno, Stabile, and Morawska 2020; CDC 2020c; SAGE 2020), which is particularly relevant for drivers who spend several hours inside vehicles. In the absence of specific guidance about ventilation in public transportation vehicles, the United Kingdom has recommended following the ventilation flow rate guidelines for buildings, which is $8-10 \mathrm{l} / \mathrm{s} /$ person (litres per second per person) of fresh air, without recirculation (SAGE 2020).

\section{Economic and Social Effects of the COVID-19 Outbreak in Public Transportation}

\section{Financial Adversity}

In a matter of weeks, the COVID-19 pandemic became the largest economic crisis for public transportation services in decades. The severe decline in public transportation demand due to COVID-19 has been combined with increased costs due to new hygiene and cleaning standards. Under these conditions, several public transportation agencies are struggling financially, putting pressure on governments. The largest US public transit agency, New York's Metropolitan Transportation Authority (MTA), is seeking a \$4 billion bailout due to the COVID-19 pandemic (Goldbaum 2020). In other countries like Chile, the government has agreed to compensate bus operators for the loss in demand (up to 80\%) in its capital city, Santiago (DF 2020). The 
Dutch government has allocated $€ 1.5$ billion for compensating the Dutch Railways (NS) and the three urban public transport operators in Amsterdam, the Hague, and Rotterdam (NOS 2020). The Swedish government transferred 3 billion SEK to cover nationwide income losses from reduced ticket sales (Sverigesradio 2020). An additional problem for public transportation agencies seeking financial relief is that the COVID-19 pandemic negatively impacts the availability of public funds, given that governments face a large number of social needs requiring financial support (e.g., unemployment, risk of bankruptcy for small businesses, hospitals, and health care) while expecting a reduction in tax intakes. In this context, public transportation must compete against several other social needs for financial support.

Regarding fare payment, new rules for the use of public transportation may have undesired effects on reducing revenues. Compulsory rear-door boarding can be recommended to avoid contact between drivers and passengers, if drivers are not physically separated from passengers. This policy has been implemented in cities such as Santiago and Montreal, as well as in the Netherlands, since March 2020. But in systems that rely on passengers boarding at the front door for onboard fare payment, rear-door boarding imposes financial risks such as inducing or forcing free rides. Apart from this issue, traditional ticket inspection, with inspectors approaching passengers to check if they hold a valid ticket or travel pass, may not be possible due to increased contagion risk (UITP 2020). This may result in an increase in fare evasion if no alternative payment method is available.

The largest problem to be faced due to the decrease in demand and the resulting financial pressure in public transport is the possibility of bankruptcy for public transportation providers, if not rescued. Some countries may have the means to support public transport, other countries may not. In low-income and developing countries, public transportation is usually unregulated or poorly regulated, without proper standards of safety or hygiene and no public subsidies, where driver income depends directly on the number of passengers carried daily (Tirachini 2019; Gwilliam 1999). The financial conditions of such systems and of the people delivering this type of public transportation service is highly dependent on the final duration of the COVID-19 crisis.

\section{Social Equity}

Working from home during the COVID-19 crisis has been shown to be mostly a privilege of higher income jobs, as reported in data from different countries including the United States (Valentino-DeVries, Lu, and Dance 2020), Canada (Tanguay and Lachapelle 2020), and Chile (Astroza et al. 2020; MOVID-19 2020). Based on survey data collected from 20,000 respondents in Germany, the United Kingdom, and the United States, AdamsPrassl et al. (2020) concluded that less educated workers and women are more negatively impacted by the ramifications of the pandemic on the labor market. The long-term impacts of the pandemic crisis are expected to exacerbate disparities not only within countries, but also between countries due to their different levels of resourcefulness in recovering from the crisis (The Economist 2020).

In this context, the vision of public transportation as a motor of social integration rather than of social segregation seems more distant today than ever. With the COVID-19 pandemic, people have abandoned public transportation, but not uniformly: high-income groups have left public transportation in larger numbers. A recent survey comparing trips made in the last week pre-coronavirus crisis in Santiago versus the first week with nationwide measures to contain the virus in March 2020 found that people from higher-income households were the highest number who stopped traveling by public transport. While trips on public transportation fell by between $30 \%$ and $40 \%$ for people in the lowest income households, the decrease in public transportation use was greater than $70 \%$ for the highest income households (estimation based on data from Tirachini et al. 2020). These numbers quantify the assertion that the people who leave public transportation are mainly those who 
have the option to do so-by working from home, by being able to pay for alternative means of transportation, and by shopping online-while those who continue to travel by public transportation are largely people with lower incomes. This difference in the rate of adaptation in travel behavior between different social groups is likely to continue in some ways throughout the post-crisis period. Consequently, improving public transportation today is, more than ever, a matter of social equity.

\section{Sustainable Mobility}

The sharp reduction in public transportation demand due to the new physical distance behaviors and the fear of COVID-19 contagion poses several questions for the future sustainability of mobility in cities. Designing a plan to make public transportation safe for a period of time (post-crisis) that is likely to be prolonged (as long as there is no widespread immunity to the new virus) requires several coordinated actions from policy makers, public transportation agencies, workers, and users. The objective should be to ensure that public transportation is as safe as possible and that it can accommodate and attract more people than those who have no viable alternative.

If buses and trains are running almost empty in the COVID-19 era, then the economic and environmental efficiency argument for promoting public transportation is severely challenged, and the only argument remaining would be providing mobility to those who have to travel because public transportation is their only option. If new physical distance and occupancy rules are imposed, a valid study is the demand threshold (i.e., break-even point) in public transportation vehicle occupancy that makes buses more efficient than private cars in terms of energy consumption, congestion, and pollution. Consider road space consumption, for example. Before the onset of the COVID-19 crisis, buses in Santiago carried between 28 and 65 passengers on average (taking into account peak and off-peak periods), while cars had an average occupancy between 1.4 and 1.5 pax/ veh (SECTRA 2013). Therefore, considering a passenger car equivalency (PCE) of two to three cars per bus, it is estimated that car users occupy between 10 and 15 times more road space than bus users. Therefore, average bus occupancy can be largely reduced while remaining a more efficient mode in the use of road space than traveling by car.

\section{The Way Forward: Policy Directions and a Research Agenda}

In the following, we identify and discuss key directions for potential policy interventions as well as areas that need advancements in knowledge. This section outlines a research agenda to address an array of identified research gaps, questions pertaining to public health considerations, and measures to reduce crowding in public transportation.

\section{Public Health Considerations in Transportation Planning Incorporating Public Health Considerations into Service Planning}

Passenger transportation where people share the same facilities and vehicles is especially prone to virus spreading when proper measures are not taken. This is particularly true for mass public transit where many passengers with diverse origins and destinations are traveling in crowded conditions. The question is then, what costs should the public transportation system bear-in the form of preventive measures and prolonged travel times-to reduce the public health risks associated with contagion. Although it brings unease, societies have limits as to how much they are willing to sacrifice to save lives. Regardless of the assumed risk level, this requires making moral choices, which are by no means new in the transportation policy domain, as pointed out by 
Chorus (2020). Think for instance of deciding whether to invest in a connection that will save passenger hours as opposed to a safety measure expected to reduce the risk of fatal accidents. Also, in the case of making decisions in the context of COVID-19, this involves trade-offs between abstract but grave risks versus the experience and annoyances for many. Hence the need for methods to support evidence-based decision making and for professionals to convey to decision makers and the public the dilemmas and decisions made.

\section{Physical Distancing in Public Transportation}

During the COVID-19 lockdown period, it was generally agreed that travel must be minimized, allowing only essential or unavoidable trips. As activities resume in the post-lockdown period, it gives rise to the question of physical distancing in public transport. The scarce empirical research available hitherto does not provide conclusive evidence on the effect of physical distancing in closed environments such as public transportation facilities and vehicles. There is, albeit limited, evidence showing that the relevance of physical distancing in public transport can be greatly reduced if other non-pharmaceutical measures are enforced, such as the correct use of face masks, enhanced hygiene, or even a prohibition of talking (Singapore case). On one hand, if contagion in indoor environments can occur at distances greater than two meters due to airborne transmission, as reported by Shen et al. (2020) and further discussed in recent epidemiological contributions (Prather, Wang, and Schooley 2020; Morawska and Cao 2020; Setti et al. 2020), then there is still a risk of virus spreading without wearing a face mask. In the presence of an infected passenger, physical distancing can help reduce the number of people infected but not prevent infection altogether when passengers do not wear masks. On the other hand, the latest epidemiological research shows that masks are effective in preventing or at least significantly reducing COVID-19 virus spread (Leung et al. 2020; Prather, Wang, and Schooley 2020; Chu et al. 2020). There are public transportation systems currently running large occupancies with passenger spacing below the twometer physical distance rule and no COVID-19 outbreaks attributed to public transportation when everyone wears masks, as recently reported for Japan. In that country, it was recently found that most COVID-19 contagion clusters originated in places where people gather, eat, drink, chat, and sing, such as gyms, pubs, live music venues, and karaoke rooms. No cluster was linked to commuter trains. The fact that close-range conversation among strangers in public transportation is infrequent has been hypothesized by virologist Hitoshi Oshitani as one of the explanations for these findings (Normile 2020). This type of result led Singapore to its decision of not enforcing strict physical distancing rules in public transportation but requiring passengers to wear face masks and not talk to each other.

Even though the safety gains from universal adoption of face masks are potentially large, it is unknown how much safer a public transportation vehicle or station is if all passengers wear different types of masks (surgical, cloth, N95) at different stages of the pandemic, versus if only a subset of them does it. This is a matter of utmost relevance because it can help in defining a "reasonable" occupancy level for public transport, an element that has significant economic, operational, and social implications. Put differently, if a physical distance of two meters does not properly work in public transportation vehicles when people do not wear masks, what should be the maximum passenger capacity of vehicles if all people use masks properly? The current experience in large cities in Asia, such as Tokyo and Seoul, shows that a physical distance shorter than one meter in public transportation seems to work well under universal mask use and high hygiene standards; however, the current prevalence of the virus in those places is unknown. The evolution of such an approach to public transportation use, without setting strong physical distancing rules, should be closely followed in the near future to understand the conditions that would allow for its replication in other cities around the world. 
It is worth stressing that solid evidence on the COVID-19 transmission risk in public transportation under different use and operation rules (including the adoption of preventive strategies) is still scarce, and new insights are expected to be gained in the coming months. The problem of new maximum occupancy standards due to new physical distancing requirements is a multifaceted challenge that depends on the use of face masks, sanitization, and ventilation, among other factors. However, conditions are likely to be less clear-cut with some passengers not (properly) wearing masks. We therefore assume in the following that some form of physical distancing may be needed, which is the current reality in many countries.

\section{Trade-offs between Service Efficiency, Effectiveness, and Robustness in the Context of COVID-19}

As clearly and painfully demonstrated in this pandemic crisis, the connectivity offered by all modes of transportation is not only an asset and a catalyst for the exchange of ideas and goods, but also a potential catalyst for adversity, such as a virus. System robustness is measured in terms of its capacity to withstand shock and recover functionality. The provision of public transportation services in the era of the pandemic and its aftermath involves trade-offs between effectiveness (defined in terms of the accessibility and level-of-service offered), robustness (the health risks associated with traveling by public transport), and efficiency (the amount of resources needed to offer a given service supply). As is often the case, there is an inherent conflict between efficiency and robustness since the latter requires designing larger margins and reserves, which imply redundancy under normal circumstances. This is particularly stressing given the already adverse financial conditions experienced by many public transport service providers worldwide. In the context of complying with physical distancing measures and thus a reduced capacity standard, the robust solution will involve not only inefficiency from an operator's perspective (i.e., requiring additional resources), but also ineffectiveness since it results in a deterioration of the level-of-service due to expected less frequency and hence longer waiting times in the postcrisis phase.

\section{Measuring System Resilience and Its Ability to Restore Functionality}

Given the importance of public transportation systems as critical infrastructure and to society at large (Homeland Security 2010), it is essential to devise measures to mitigate the impacts of virus spreading in public transportation systems, while maintaining their functionality as critical infrastructure to the extent possible. The bathtub model proposed by McDaniels et al. (2008) offers a conceptual framework for analyzing the evolution of system performance in the event of a disruption. In the context of public transport, system performance can be measured in terms of the original capacity share that is provisioned, total number of passengers transported, total passenger-km, and total passenger time losses attributed to the disruption. The conceptualization and analysis of the robustness and resilience of public transportation systems has mostly been limited to supply performance and passenger accessibility and connectivity (Jenelius and Cats 2015; Bešinović 2020). The pandemic produced a shock to the system that caused an abrupt reduction in system performance with consequences to its core functionalities. Some parts of the world are currently experiencing different phases of the recovery period. The recovery period sees an increase in system performance, although there is no guarantee that (1) system recovery will follow a monotonic pattern, setbacks such as more restrictive measures introduced following a so-called "second wave," and (2) system performance will recover to its original level (i.e., the recovery may yield a new normal). This calls for the development of concepts and methods to assess system resilience while encompassing impacts for public health in addition to accessibility, equity, sustainability, and financial viability. 


\section{Assessing the Spread of Virus in Public Transportation}

Understanding and quantifying the spread of virus in public transportation systems is essential for evaluating the public health consequences of alternative scenarios and strategies. There is therefore an urgent need to couple transportation models and epidemiological models in order to analyze the resulting contact graphs and their spatial consequences (Barabási 2014; Colizza et al. 2007). The contact network reflects the set of passengers a person potentially encounters during a public transportation journey. The transportation model will assign travel demand to the service network and that output will be used as input to the epidemiological model, which then updates the states of segments of the travel demand population in relation to virus carrying. Each passenger on any given day may be characterized by one of the following states: susceptible (not infected), infected (and traveling), quarantined (infected and not traveling), and immune (and traveling again). Passenger demand can then be reassigned to the network to analyze the evolution of the virus spreading and obtain key performance indicators, such as the share of the passenger population that has been infected or the number of days needed for nullifying the number of new cases. Since virus spreading requires physical proximity to an infected passenger, it is essential to analyze individual passenger trajectories and the resulting crowding levels. Krishnakumari and Cats (2020) demonstrated how this can be done using detailed smart card trajectories. They estimated the crowding conditions that each passenger experiences on any segment of the journey and the probability that a person is in proximity to someone who is infected, based on the trajectories of those assumed initially infected. Such modeling capabilities allow testing the potential consequences of various demand levels, service provision, and assumed virus spreading characteristics to support the design of exit strategies and postpandemic realities.

\section{Contact Tracing to Reduce the Risk of Virus Spreading in Public Transport}

Medical developments such as testing more of the public and faster diagnoses will significantly impact the potential spread of the virus in public transport by reducing the number of infected passengers traveling and therefore reducing the health risk to others. To this end, contact tracing can also support shortening the exposure period for passengers who are potential carriers of the virus prior to diagnosis. Governments worldwide have introduced or are in the process of introducing contact tracing apps designed to facilitate this. In the context of public transport, smart card data validations may be used for contact tracing in public transportation systems as demonstrated by Krishnakumari and Cats (2020) for the Washington DC Metro system. Passively collected fare data offers a unique source for conducting contact tracing research and supports the identification of contact networks based on recorded or inferred passenger trajectories. In systems that require tap-in only and/or offer station-based (rather than vehicle-based) validation, the application of alighting station and vehicle inference methods will be instrumental.

\section{Avoiding the Crowds: Accommodating Physical Distancing Regulations Implications of Physical Distancing on Service Capacity}

The public transportation sector is currently focusing on adjusting services to adhere to physical distancing requirements as well as vehicle and station cleanliness, to comply with governmental instructions, and to reduce public health risks. As discussed above, however, there is currently no conclusive evidence on the relevance of strong physical distance rules (as two meters is likely not enough in closed environments if people do not wear masks, and there are public transport systems with large occupancy levels in which everyone wears masks that have good results). Complying with physical distancing requirements comes at the cost of a 
dramatic decrease in the service capacity offered and consequently the system's ability to satisfy demand. For example, assuming that passengers are spaced across platforms and metro trains seeking to ensure a minimum distance of 1.5 meters (approximately 5 feet) from any fellow traveler, this implies a capacity of 312 passengers, a reduction of more than $80 \%$ for the Washington DC Metro (Krishnakumari and Cats 2020). Similarly, a maximum capacity of 18-20 passengers can be suggested for a standard 12-meter-long bus as a way to keep current common distance (GIZ 2020). However, any new COVID-19 induced capacity guidelines should be revisited and reassessed as the pandemic evolves and robust epidemiological knowledge becomes available. In many systems, increasing capacity through vehicles per hour or per day (as a way to counterbalance per vehicle capacity reduction) is not an option, either because services already run at full capacity in peak periods or because of a shortage in resources (lack of more vehicles, drivers, and operators). This might be particularly challenging in the upcoming period because of limited budgets due to reduced revenue, reduced driver availability due to the pandemic itself, or due to the need to protect drivers who are at higher risk (e.g., workers older than 60 with chronic diseases). There might also be requirements from drivers' unions to reduce working times and the number of shifts during the pandemic to reduce exposure to the virus. Dealing with the possible absenteeism of staff due to COVID-19 related issues is a common concern of public transportation operators (UITP 2020).

\section{Redesigning Services to Accommodate Prevailing Demand Patterns and Capacity Limitations}

Public transportation services may be redesigned to more efficiently and effectively accommodate passenger demand given the new, more restrictive capacity limitations. For example, service frequencies may be reset to maximize the share of passenger demand that can be accommodated as demonstrated by Gkiotsalitis and Cats (2020) for the Washington DC Metro network. Service redesign may also extend beyond the reallocation to existing services to involve changes in service configuration; for example, in terms of stopping patterns and short-turnings, to better adjust supply to uneven spatial patterns of demand (Tirachini, Cortés, and Jara-Díaz 2011). This calls for the potential introduction of physical distancing constraints into strategic, tactical, and operational decisions, as well as accounting for their consequences.

Leaving parts of the travel demand unserved has equity ramifications that should be assessed and integrated into the decision-making process. On-demand transportation services may be used to cater to unserved demand by line-based public transport. Traveling by means of on-demand shared services is expected to result in a contact network of limited size (Kucharski and Cats 2020). Furthermore, in addition to transporting passengers otherwise left behind, on-demand services offer door-to-door transportation for users in risk groups such as the elderly and for healthcare workers. Arrangements for shared-mobility companies to provide exclusive services to healthcare workers have already been implemented in countries such as Mexico (Jetty 2020) and Germany (Carey 2020).

\section{Effectively Managing Limited Capacity}

There are several ways to manage scarce resources. One option is to let people queue for these services, possibly denied several times before they can board a vehicle. This will not only severely prolong travel times, make service unpredictable, and lead to dissatisfaction, but will also pose public health risks with large crowds queuing. An alternative is to restrict access. Depending on the service type and fare validation technology, reservation systems might be deployed committing passengers to travel during certain time periods or on certain trajectories, or better still, to specific itineraries. This will assist in managing service capacities, thus 
ensuring compliance with physical distancing requirements, and will limit the number of passengers that each passenger is exposed to over a longer period. However, reservation systems come at the cost of limiting travelers' spontaneity (i.e., inducing scheduling delays). The feasibility of such a solution is likely to be limited to systems where digital billing and subscription capabilities are already available. Access could be based on setting priorities or even restrictions. For example, trips could be prioritized or restricted to essential workers such as medical support staff and occupational users who are not able to perform their work remotely, mitigating some of the social equity ramifications. Certain time periods might be restricted for certain user groups, such as allowing only the elderly to travel between 10 a.m. and 4 p.m. Such a prioritization or restriction should be made by the local policy makers. Alternatively, pricing can be used as an instrument to manage capacity. For example, greater discounts might be offered in the off-peak periods to stimulate passengers who can shift their departure time to do so and thereby reduce crowding levels in periods when capacity is scarce. Mobility as a Service (MaaS) ecosystems may play a key role in enabling and facilitating a smooth use of different (new) modes by providing an integrated platform for information and payments. In addition, there could be a role for MaaS platforms to facilitate a potential booking system for public transport, and to apply different fares and priorities for different sectors or risk groups.

\section{Effectively Managing Crowding to Reduce Public Health Risks}

Since physical proximity is currently assumed to be the precondition for virus spreading, crowding management is paramount to combating it. This applies to all areas of the public transportation system, including platforms and station walkways in addition to vehicles, so as to minimize crowding during all parts of the passengers' journey: walking, waiting, traveling onboard, and transferring. Crowding management measures at stations such as one-way entrances, passages, and staircases can help isolate flows and reduce the physical interaction between passengers. Similarly, designated vehicle doors might be used for boarding and alighting, although this measure will likely increase dwell time at stops where boarding from all doors was previously allowed (Jara-Díaz and Tirachini 2013; West and Cats 2017).

Public transportation priority and control measures can also play a critical role in mitigating passenger crowding. In the post-lockdown period, congestion may increase if not properly managed because of the migration of travelers from public transportation to cars. As congestion increases, operational measures to support public transportation will be more necessary than ever. Dedicated bus lanes would not only reduce operator costs and travel time for public transportation users, but also reduce crowding on vehicles and at bus stops and stations. If the bus fleet is kept constant, a reduction in travel time will be translated into a proportional reduction in average occupancy levels per vehicle, due to the increase in service frequency. At the same time, as the irregularity of headways between buses induces unnecessary overcrowding (a half-empty bus followed by a full bus), even if the aggregate capacity of the system is sufficient to satisfy the demand for public transportation trips, measures to control bus headway to mitigate bunching will become more relevant than ever during the COVID-19 pandemic. Strategies to deal with bus bunching include holding, station skipping, and speed control (Muñoz et al. 2013; Hickman 2001).

\section{Opportunities for Spreading Passenger Demand}

Public transportation demand is usually derived demand, meaning people travel because of the activities they need to perform at the destination. Therefore, reducing occupancy levels at stations and in vehicles is not achievable only by means of supply-oriented measures, but requires also the deployment of demand management measures. Effectively, all measures are aimed at reducing the size and connectivity of the contact 
networks resulting from public transportation journeys. Encouraging working from home and refraining from nonessential travel are among the most important measures. With the gradual opening in the post-lockdown phase, it is inevitable that demand will exceed supply in the peak hours on the high-demand services given the greatly reduced capacity of public transportation services under physical distancing requirements. It is therefore key to try and distribute services over time and space as much as possible. Here it is important to coordinate exit strategy plans of different sectors in the economy and society to try and schedule working, studying, and shopping patterns to spread the demand over a longer period. This requires coordination among stakeholders and should continue to be beneficial when the COVID-19 crisis has passed. Notwithstanding, it is expected that capacity of certain public transportation services during certain time periods will remain a resource for which there is more demand than the supply can offer.

\section{The Potential Role of Travel Information on Mitigating Crowding}

Information on onboard crowding conditions is becoming increasingly available. Several travel apps (e.g., Google Maps Transit service, Moovit) provide crowding information based on historical user feedback on crowding experience. Moreover, apps developed by individual service providers such as the Dutch railways, Tokyo railways, and Singapore buses distribute crowding information based on real-time data of vehicle occupancy loads (e.g., from weight sensors) (Hänseler et al. 2020). In contrast, implementations of at-stop crowding information displays regarding upcoming departures have been hitherto limited. Passenger reluctance to ride a crowded vehicle is likely to be much higher due to the pandemic, reflected in larger crowding penalties than previously reported (Hörcher, Graham, and Anderson 2017; Tirachini et al. 2017; Yap, Cats, and van Arem 2020). Consequently, more passengers are expected to seek crowding information and adjust their travel plans accordingly. This can prove to be an effective means of distributing travel demand over the available supply. A key challenge will be to ensure that the reliability of the provisioned information is not hampered by an over-response, defeating its purpose. This calls for the development of demand-anticipatory travel information schemes inspired by developments in the car traffic context, where this has been a subject of considerable research (Dong, Mahmassani, and Lu 2006).

\section{Behavioral Responses and Adaptation Exercised by Passengers}

Passengers may exercise a variety of behavioral adaptations in response to COVID-19 pandemic conditions and related lockdown and exit strategies. The main motivation is to avoid exposure to the virus. In the absence of better information, this often implies following the principle of avoiding crowds. This can impact all travel choices, from altering routes to less congested ones, changing departure time to avoid the peaks, mode shift to privately used (and preferably owned) modes, changing trip destination (e.g., to less crowded stores), or refraining from traveling altogether (e.g., e-shopping). All these decisions have significant consequences for travel patterns and ridership. The population's willingness and ability to exercise such adaption varies considerably, depending on personal preferences as well as household income and composition, logistics, working hours flexibility, working from home, digital proficiency, and vehicle availability. All of this means there is considerable inequality in people's ability to avoid the crowds if they so desire, as supported by some preliminary evidence.

\section{Concluding Remarks}

The COVID-19 pandemic poses great challenges for public transportation systems worldwide. This paper has reviewed the available evidence as it pertains to the influence of several factors on reducing or increasing the 
COVID-19 contagion risk in public transportation, including the occupancy levels of vehicles and stations, the exposure time (trip length), the enforcement of face mask use, and the application of enhanced hygiene standards (including sanitization and ventilation). The ongoing pandemic forces policy makers to make decisions in the context of uncertainty.

The absolute risk of contagion is highly dependent on the disease prevalence in the community at any specific time, therefore any restrictions or regulations on public transportation use should be tailored differently depending on the phase of an outbreak. A detailed analysis on this issue is required, identifying levels of contagion that make public transportation use increasingly risky from a public health perspective. Notwithstanding, some promising evidence is emerging as to how to make public transportation safe or at least significantly decrease the contagion risk, with implications particularly for the post-lockdown phase. It is still too early to arrive at definitive conclusions; more research is needed to assess the true level of safety in public transportation when proper virus containment measures are taken at different stages of the pandemic. This is a matter of uttermost relevance because if public transportation is perceived as unsafe and unhealthy by large segments of the population, it will not be able to fulfill the societal roles that it is set to serve, including accessibility, sustainability, and equity. Certain developments such as finding a vaccine or lifting lockdown measures lie outside the control of the public transportation sector, but many of the measures discussed above are within the principal responsibility of public transportation service providers. This will also help assure the public that adequate measures are taken. Communication, public relations, and enforcement of safety measures are especially important during this period.

There is a risk that if the public transportation sector is viewed as poorly transitioning to two-meter distancing conditions, that perceptions of public transportation as unhealthy will gain ground and might be sustained even in the aftermath, resulting in the formation of new habits. Our societies need public transportation services to prosper and to address key societal challenges that are paramount and persistent. It is therefore critical to avoid contributing to stereotyping the use of public transportation as unhealthy, which may outlive the pandemic itself and hinder the long-term prospects of public transportation services.

\section{Acknowledgements}

Support from ANID Chile (Grant PIA/BASAL AFB180003) is acknowledged. The authors are indebted to Cristobal Cuadrado (School of Public Health, Universidad de Chile) and three anonymous referees for comments that helped to improve the paper. All views and any errors are the authors' responsibility alone.

\section{References}

Adams-Prassl, A., T. Boneva, M. Golin, and C. Rauh. 2020. "Inequality in the Impact of the Coronavirus Shock: Evidence from Real Time Surveys." Cambridge-INET Working Paper WP2018.

Astroza, S., A. Tirachini, R. Hurtubia, J. A. Carrasco, A. Guevara, M. Munizaga, M. Figueroa, and V. Torres. 2020. "Mobility Changes, Teleworking, and Remote Communication during the COVID-19 Pandemic in Chile." Transport Findings, July. https://doi.org/10.32866/001c.13489.

Barabási, A.-L. 2014. Network Science Spreading Phenomena. Accessed June 3, 2020. https://pdfs.semanticscholar. org/5790/86aced0f47981d2c3c85117808fd64c70cc9.pdf.

Bešinović, N. 2020. "Resilience in railway transport systems: a literature review and research agenda." Transport Reviews 40 (4): 457-78. doi:10.1080/01441647.2020.1728419. 
Buonanno, G., L. Stabile, and L. Morawska. 2020. "Estimation of airborne viral emission: Quanta emission rate of SARS-CoV-2 for infection risk assessment." Environment International 141 (August 2020): 105794. https:// doi.org/10.1016/j.envint.2020.105794.

CDC. 2020a. "Coronavirus Disease 2019 (COVID-19): How to Protect Yourself \& Others." Centers for Disease Control and Prevention (CDC). Last Updated July 31, 2020. https://www.cdc.gov/coronavirus/2019-ncov/ prevent-getting-sick/prevention.html?CDC_AA_refVal=https\%3A\%.

CDC. 2020b. "Coronavirus Disease 2019 (COVID-19): COVID-19 Employer Information for Office Buildings." Centers for Disease Control and Prevention (CDC). Last Updated July 9, 2020. https://www.cdc.gov/ coronavirus/2019-ncov/community/office-buildings.html.

CDC. 2020c. "Coronavirus Disease 2019 (COVID-19): Protect Yourself When Using Transportation." Centers for Disease Control and Prevention (CDC). Last Updated August 3, 2020. https://www.cdc.gov/ coronavirus/2019-ncov/daily-life-coping/using-transportation.html.

Chorus, C. 2020. "Moral decisions and the corona crisis - insights from the BEHAVE-research program." BEHAVE. March 28, 2020. http://behave.tbm.tudelft.nl/index.php/2020/03/28/moral-decisions-and-thecorona-crisis-insights-from-the-behave-research-program/.

Chu, D. K., E. A. Akl, S. Duda, K. Solo, S. Yaacoub, H. J. Schünemann, et al. 2020. "Physical distancing, face masks, and eye protection to prevent person-to-person transmission of SARS-CoV-2 and COVID-19: a systematic review and meta-analysis." The Lancet 395 (10242): 1973-87. doi:10.1016/S0140-6736(20)31142-9.

Carey, C. 2020. "ViaVan offers free rides to Berlin healthcare workers." CitiesToday. March 25, 2020. https://citiestoday.com/viavan-offers-free-rides-for-berlin-healthcare-staff/.

Colizza, V., M. Barthélemy, A. Barrat, and A. Vespignani. 2007. "Epidemic modeling in complex realities." Comptes rendus biologies 330 (4): 364-74. doi:10.1016/j.crvi.2007.02.014.

DF. 2020. "MTT agrees payment mechanism with former Transantiago operators due to drastic drop in revenue." Diario Financiero. Accessed May 22, 2020. https://www.df.cl/noticias/empresas/industria/mtt-acuerdamecanismo-de-pago-con-operadores-del-ex-transantiago-ante/2020-05-19/195247.html.

DfT. 2020. "Coronavirus (COVID-19): safer travel guidance for passengers." Department for Transport, United Kingdom. Last updated July 25, 2020. https://www.gov.uk/guidance/coronavirus-covid-19-safer-travelguidance-for-passengers.

Dong, J., H. S. Mahmassani, and C-C. Lu. 2006. "How Reliable is this Route?: Predictive Travel Time and Reliability for Anticipatory Traveler Information Systems." Transportation Research Record: Journal of the Transportation Research Board 1980 (1): 117-25. doi: 10.1177/0361198106198000116.

Eikenberry, S. E., M. Mancuso, E. Iboi, T. Phan, K. Eikenberry, Y. Kuang, et al. 2020. "To mask or not to mask: Modeling the potential for face mask use by the general public to curtail the COVID-19 pandemic." Infectious Disease Modelling 5 (2020): 293-308. https://doi.org/10.1016/j.idm.2020.04.001.

Fa-Chun, J., J. Xiao-Lin, W. Zhao-Guo, M. Zhao-Hai, S. Shou-Feng, et al. 2020. "Detection of Severe Acute Respiratory Syndrome Coronavirus 2 RNA on Surfaces in Quarantine Rooms." Emerging Infectious Diseases 26 (9): 2162-2164. doi:10.3201/eid2609.201435.

Ferretti, L., C. Wymant, M. Kendall, L. Zhao, A. Nurtay, L. Abeler-Dörner, et al. 2020. "Quantifying SARS-CoV-2 transmission suggests epidemic control with digital contact tracing." Science 368 (6491). doi:10.1126/science. abb6936. 
GIZ. 2020. "Standard Operating Procedures (SOPs) for Bus Transport post COVID-19 Lockdown." Accessed May 4, 2020. https://www.sutp.org/publications/standard-operating-procedures-sops-for-bus-transport-postcovid19-lockdown/.

Gkiotsalitis, K., and O. Cats. 2020. "Optimal frequency setting of metro services in the age of COVID-19 distancing measures." Preprint, May 26, 2020. doi:10.13140/RG.2.2.35560.70406.

Goldbaum, C. 2020. "M.T.A., Citing Huge Drop in Riders, Seeks \$4 Billion Virus Bailout." New York Times. March 17, 2020. https://www.nytimes.com/2020/03/17/nyregion/coronavirus-nyc-subway-federal-aid-.html.

Google. 2020. "COVID-19 Community Mobility Reports." Accessed June 3, 2020. https://www.google.com/ covid19/mobility/index.html?hl=en.

Greenhalgh, T., M. B. Schmid, T. Czypionka, D. Bassler, and L. Gruer. 2020. "Face masks for the public during the covid-19 crisis." BMJ (2020) 369: m1435. doi:10.1136/bmj.m1435.

Gwilliam, K. 1999. "Public Transport in the Developing World - Quo Vadis?" International Conference Series on Competition and Ownership in Land Passenger Transport - 1999. Cape Town, South Africa - Thredbo 6.

Han, Q., Q. Lin, Z. Ni, and L. You. 2020. "Uncertainties about the transmission routes of 2019 novel coronavirus." Letter to the Editor, March 4, 2020. Influenza and other respiratory viruses 14 (4): 470-71. doi: 10.1111/ irv.12735.

Hänseler, F. S., J. P. A. van den Heuvel, O. Cats, W. Daamen, and S. P. Hoogendoorn. 2020. "A passengerpedestrian model to assess platform and train usage from automated data." Transportation Research Part A: Policy and Practice 132 (February 2020): 948-68. https://doi.org/10.1016/j.tra.2019.12.032.

Hickman, M. D. 2001. "An Analytic Stochastic Model for the Transit Vehicle Holding Problem." Transportation Science 35 (3): 215-37.

Homeland Security. 2010. Transportation Systems Sector-Specific Plan: An Annex to the National Infrastructure Protection Plan. U.S. Department of Homeland Security.

Hörcher, D., D. J. Graham, and R. J. Anderson. 2017. "Crowding cost estimation with large scale smart card and vehicle location data." Transportation Research Part B: Methodological 95 (January 2017): 105-25. https:// doi.org/10.1016/j.trb.2016.10.015.

How, M., and S. Thiagarajan. 2020. "Why you can board a crowded MRT train but cannot meet your friends: Lawrence Wong explains." Mothership. June 8, 2020. https://mothership.sg/2020/06/why-still-cannot-seefriends-covid/.

Jara-Díaz, S. R., and A. Tirachini. 2013. "Urban Bus Transport: Open All Doors for Boarding." Journal of Transport Economics and Policy 47 (1): 91-106.

Javid, B., M. P. Weekes, and N. J. Matheson. 2020. "Covid-19: should the public wear face masks?" BMJ (2020) 369: m1442. doi:10.1136/bmj.m1442.

Jenelius, E., and O. Cats. 2015. "The value of new public transport links for network robustness and redundancy." Transportmetrica A: Transport Science 11 (9): 819-35. doi:10.1080/23249935.2015.1087232.

Jetty. 2020. "Jetty supports the transportation of hospital personnel in Toluca." Accessed June 3, 2020. https:// www.jetty.mx/update/2020/05/25/jetty-apoyo-personal-medico-toluca.html. 
Jianyun, L., G. Jieni, L. Kuibiao, X. Conghui, S. Wenzhe, L. Zhisheng, et al. 2020. "COVID-19 Outbreak Associated with Air Conditioning in Restaurant, Guangzhou, China, 2020." Emerging Infectious Diseases 26 (7): 1628-31. doi:10.3201/eid2607.200764.

Konda, A., A. Prakash, G. A. Moss, M. Schmoldt, G. D. Grant, and S. Guha. 2020. "Aerosol Filtration Efficiency of Common Fabrics Used in Respiratory Cloth Masks." ACS Nano 14 (5): 6339-47. doi:10.1021/ acsnano.0c03252.

Krishnakumari, P., and O. Cats. 2020. "Virus Spreading in Public Transport Networks." Working paper. Transport Institute TU Delft, April 30, 2020.

Kucharski, R., and O. Cats. 2020. "On Virus Spreading Processes in Ride-Sharing Networks." Preprint. SmartPTLab, Department of Transport \& Planning, TU Delft.

Leung, N. H. L., D. K. W. Chu, E. Y. C. Shiu, K.-H. Chan, J. J. McDevitt, B. J. P. Hau, et al. 2020. "Respiratory virus shedding in exhaled breath and efficacy of face masks." Nature Medicine 26 (April 2020): 676-80. doi:10.1038/s41591-020-0843-2.

McDaniels, T., S. Chang, D. Cole, J. Mikawoz, and H. Longstaff. 2008. "Fostering resilience to extreme events within infrastructure systems: Characterizing decision contexts for mitigation and adaptation." Global Environmental Change 18 (2): 310-18. https://doi.org/10.1016/j.gloenvcha.2008.03.001.

Molloy, J., T. Schatzmann, B. Schoeman, C. Tchervenkov, B. Hintermann, and K. W. Axhausen. 2020. "Observed impacts of COVID-19 on travel behaviour in Switzerland based on a large GPS panel." Working paper. IVT, ETH Zurich.

Morawska, L., and J. Cao. 2020. "Airborne transmission of SARS-CoV-2: The world should face the reality." Environment International 139: 105730. doi:10.1016/j.envint.2020.105730.

MOVID-19. 2020. "What has been the response of the population to the quarantines? The impact of inequalities on the effectiveness of health policies." National Monitoring of COVID-19 Symptoms and Practices in Chile (MOVID-19). June 9, 2020. https://www.movid19.cl/informes/mesasocial3.html.

Muñoz, J. C., C. E. Cortés, R. Giesen, D. Sáez, F. Delgado, F. Valencia, and A. Cipriano. 2013. "Comparison of dynamic control strategies for transit operations." Transportation Research Part C: Emerging Technologies 28 (March 2013): 101-13. https://doi.org/10.1016/j.trc.2012.12.010.

Musselwhite, C., E. Avineri, and Y. Susilo. 2020. "Editorial JTH 16-The Coronavirus Disease COVID-19 and implications for transport and health." Journal of Transport \& Health 16 (April 2020): 100853. doi:10.1016/j. jth.2020.100853.

Ngonghala, C. N., E. Iboi, S. Eikenberry, M. Scotch, C. R. Maclntyre, M. H. Bonds, and A. B. Gumel. 2020. "Mathematical assessment of the impact of non-pharmaceutical interventions on curtailing the 2019 novel Coronavirus." Mathematical Biosciences 325 (July 2020): 108364. https://doi.org/10.1016/j.mbs.2020.108364.

Nishiura, H., H. Oshitani, T. Kobayashi, T. Saito, T. Sunagawa, T. Matsui, T. Wakita, and M. Suzuki. 2020. "Closed environments facilitate secondary transmission of coronavirus disease 2019 (COVID-19)." medRxiv. Preprint, April 16, 2020. doi:10.1101/2020.02.28.20029272.

Normile, D. 2020. "Japan ends its COVID-19 state of emergency." Science. May 26, 2020. https://www.sciencemag. org/news/2020/05/japan-ends-its-covid-19-state-emergency. 
NOS. 2020. "1.5 billion euros in corona compensation for public transport companies." Accessed June 9, 2020. https://nos.nl/artikel/2336334-1-5-miljard-euro-coronacompensatie-voor-ov-bedrijven.html.

Prather, K. A., C. C. Wang, and R. T. Schooley. 2020. "Reducing transmission of SARS-CoV-2." Science 368 (6498): 1422-24. doi:10.1126/science.abc6197.

Qian, H., T. Miao, L. Liu, X. Zheng, D. Luo, and Y. Li. 2020. "Indoor transmission of SARS-CoV-2." medRxiv. April 7, 2020. doi:10.1101/2020.04.04.20053058.

Rijksoverheid. n.d. " Frequently asked questions about the corona virus and public transport." Accessed June 3, 2020. https://www.rijksoverheid.nl/onderwerpen/coronavirus-covid-19/verkeer-openbaar-vervoergrensstreek/openbaar-vervoer.

SAGE. 2020. "EMG: Transmission and Control of SARS-CoV-2 on Public Transport." Meeting paper. May 18, 2020. Environmental and Modelling Group (EMG) for Scientific Advisory Group for Emergencies (SAGE), United Kingdom.

SECTRA. 2013. "Measurements of traffic capacity and load profiles in trunk services in Santiago." Annual Report 2013 prepared by DICTUC.

Setti, L., F. Passarini, G. De Gennaro, P. Barbieri, M. Perrone, M. Borelli, et al. 2020. "Airborne Transmission Route of COVID-19: Why 2 Meters/6 Feet of Inter-Personal Distance Could Not Be Enough." International Journal of Environmental Research and Public Health 17 (8): 2932. doi:10.3390/ijerph17082932.

Shen, Y., C. Li, H. Dong, Z. Wang, L. Martinez, Z. Sun, A. Handel, et al. 2020. "Airborne transmission of COVID-19: epidemiologic evidence from two outbreak investigations." Preprint available at https://www.researchgate. net/publication/340418430_Airborne_transmission_of_COVID-19_epidemiologic_evidence_from_two_ outbreak_investigations.

Sverigesradio. 2020. "The government provides money so that public transport can run as usual." May 11, 2020. https://sverigesradio.se/sida/artikel.aspx?programid=4916\&artikel=7470922.

Tanguay, G. A., and U. Lachapelle. 2020. "Remote work worsens inequality by mostly helping high-income earners." The Conversation. May 10, 2020. https://theconversation.com/remote-work-worsens-inequality-bymostly-helping-high-income-earners-136160.

Terrill, M. 2020. "Shame about the cars, but Premier is right to be cautious about public transport." Sydney Morning Herald, May 19, 2020. https://www.smh.com.au/politics/nsw/shame-about-the-cars-but-premier-isright-to-be-cautious-about-public-transport-20200518-p54txr.html.

The Economist. 2020. "Covid-19 threatens Europe's success at fighting inequality." Accessed June 9, 2020. https:// www.economist.com/europe/2020/06/06/covid-19-threatens-europes-success-at-fighting-inequality.

Tirachini, A. 2019. "South America: The challenge of transition." In A Research Agenda for Transport Policy, edited by J. Stanley and D. Hensher, 118-25. Edward Elgar Publishing. https://doi.org/10.4337/978178897020 4.00023.

Tirachini, A., C. E. Cortés, and S. R. Jara-Díaz. 2011. "Optimal design and benefits of a short turning strategy for a bus corridor." Transportation 38: 169-89. https://doi.org/10.1007/s11116-010-9287-8.

Tirachini, A., A. Guevara, M. Munizaga, J. A. Carrasco, S. Astroza, and R. Hurtubia. 2020. "Survey on the effects of the COVID-19 pandemic on mobility, activities and concerns of people." Report, Complex Engineering Systems Institute (ISCI), Chile. Accessed May 4, 2020. https://isci.cl/wp-content/uploads/2020/04/EncuestaMovilidad-ISCI-Abril-2020_v02.pdf. 
Tirachini, A., R. Hurtubia, T. Dekker, and R. A. Daziano. 2017. "Estimation of crowding discomfort in public transport: Results from Santiago de Chile." Transportation Research Part A: Policy and Practice 103 (June 2017): 311-26. doi:10.1016/j.tra.2017.06.008.

UITP. 2020. "Management of COVID-19: Guidelines for Public Transport Operators." Factsheet, March 2020. International Association of Public Transport (UITP). Accessed May 4, 2020. https://www.uitp.org/ management-covid-19-guidelines-public-transport-operators.

Valentino-DeVries, J., D. Lu, and G. J. X. Dance. 2020. "Location Data Says It All: Staying at Home During Coronavirus Is a Luxury." New York Times. April 3, 2020. https://www.nytimes.com/interactive/2020/04/03/ us/coronavirus-stay-home-rich-poor.html.

van Doremalen, N., T. Bushmaker, D. H. Morris, M. G. Holbrook, A. Gamble, B. N. Williamson, et al. 2020. "Aerosol and Surface Stability of SARS-CoV-2 as Compared with SARS-CoV-1." New England Journal of Medicine 382 (16): 1564-67. doi:10.1056/NEJMc2004973.

West, J., and O. Cats. 2017. "Individual and Synergetic Effects of Transit Service Improvement Strategies: Simulation and Validation." Journal of Transportation Engineering, Part A: Systems 143 (12). doi:10.1061/ JTEPBS.0000095.

WHO. 2020a. Advice on the use of masks in the context of COVID-19: Interim guidance, 5 June 2020. World Health Organization. https://apps.who.int/iris/handle/10665/332293.

WHO. 2020b. "Coronavirus disease (COVID-19) advice for the public." World Health Organization. Last updated June 4, 2020. https://www.who.int/emergencies/diseases/novel-coronavirus-2019/advice-for-public.

Wong, Y. 2020. "To limit coronavirus risks on public transport, here's what we can learn from efforts overseas." The Conversation. March 16, 2020. https://theconversation.com/to-limit-coronavirus-risks-on-publictransport-heres-what-we-can-learn-from-efforts-overseas-133764.

Yap, M., O. Cats, and B. van Arem. 2020. "Crowding valuation in urban tram and bus transportation based on smart card data." Transportmetrica A: Transport Science 16 (1): 23-42. doi:10.1080/23249935.2018.1537319.

\section{About the Authors}

Alejandro Tirachini (Alejandro.tirachini@ing.uchile.cl) is an associate professor of civil engineering at the Universidad de Chile. He holds an MS in Transport Engineering from the Universidad de Chile and a PhD from the Institute of Transport and Logistics Studies, the University of Sydney. His main research interests include the optimal design and operation of public transport systems and the study of emerging mobility technologies with a focus on sustainable mobility. He has served in the Experts Panel of Chile's Ministry of Social Development for the examination of improvements to the methodology of cost-benefit analysis for transport projects, in the Experts Panel of the Ministry of Transport to improve the understanding of fare evasion in public transport, and in the Experts Panel of the government's MAPS Initiative (Mitigation of Climate Change and Low Carbon Transportation Development).

Oded Cats (O.Cats@tudelft.nl) is an associate professor at the Department of Transport and Planning at Delft University of Technology, the Netherlands. Dr. Cats' research is devoted to developing theories and models of multimodal passenger transport networks by combining advancements simulation and operations research, behavioural sciences, and complex network theory and modeling. Most of his work is in metropolitan public transport systems where he focuses on network dynamics and robustness, service operations and control, and passenger demand and flow distributions. Dr. Cats is the recipient of a European Research Council Starting 
Grant entitled "CriticalMaaS" and he co-directs the Smart Public Transport Lab at TU Delft, leading a research group that works closely with public transport authorities and operators. He is also editor-in-chief of the European Journal of Transport and Infrastructure Research. 